\title{
BRINCADEIRAS DA INFÂNCIA
}

\author{
Jociléia Scherer ${ }^{1}$; Janilse Nunes ${ }^{2}$
}

http://doi.org/10.48195/sepe2021-179

\section{RESUMO}

Neste trabalho aborda-se a temática acerca do brincar na infância, o qual foi proposto na disciplina de Lúdico e Criatividade I, no curso de Pedagogia da Universidade Franciscana-UFN. Desta forma, tem-se como objetivos descrever situações do brincar na infância, e ressaltar a importância do lúdico por meio das brincadeiras, que fizeram parte do cotidiano da nossa infância. Nesse sentido, foi sugerido a construção de uma sacola pedagógica que representasse as brincadeiras que foram vivenciadas no contexto infantil. A metodologia utilizada foi de um registro autobiográfico, que consiste em relatar a história da acadêmica, no que tange às brincadeiras. Partindo desse pressuposto, por meio de leituras e das minhas vivências enquanto acadêmica do Curso de Pedagogia, estagiária e criança, percebi o quanto a ludicidade é essencial para o desenvolvimento integral da criança, e imprescindibilidade de inserir o lúdico em todas as atividades dentro do ambiente escolar.

Palavras-chave: sacola pedagógica; lúdico; registro autobiográfico.

Eixo temático: Educação, Cultura e Comunicação - ECC

\section{INTRODUÇÃO}

A brincadeira deve ser considerada um recurso de aprendizagem importante para o desenvolvimento cognitivo da criança, pois, por meio da lúdico, a criança demostra toda sua agilidade, crescimento amadurecimento, nos aspectos sociais e culturais. O comportamento lúdico é essencial no processo de ensino-aprendizagem, visto que, não é apenas um momento divertido, é um momento em que se adquire o conhecimento para vida futura.

No ambiente escolar, jogos e as brincadeiras devem fazer parte do cotidiano dos alunos, a fim de que os estudantes exercitem sua imaginação, estimulem suas habilidades, desenvolvam sua personalidade, demostrando suas vontades, bem como, expressem suas emoções.

Nesse contexto, essa pesquisa analisou a importância dos momentos mágicos de brincar, por meio do desenvolvimento da disciplina Lúdico e Criatividade I, no ano

\footnotetext{
${ }^{1}$ Autor - Universidade Franciscana - jocischerer@ufn.edu.br

2 Orientadora - Universidade Franciscana - janilse@ufn.edu.br.
} 
de 2021, no Curso de Pedagogia, da Universidade Franciscana- UFN. Deste modo, foi confeccionada uma sacola baseada nas nossas brincadeiras de infância.

\subsection{SACOLA PEDAGÓGICA}

Primeiramente, escolheu-se o tamanho da sacola, cores, tecido e figuras que seriam estampadas na sua frente. Os desenhos que foram colocados na sacola foram selecionados por meio da internet, de modo que representasse todas as brincadeiras que $\mathrm{eu}^{3}$ praticava na infância, como também de outras crianças, que na época, brincavam juntas ou no mesmo espaço comigo, como irmão, amiga, amigos do irmão, flores, gramado e nuvens.

Deste modo, elegeu-se imagens que destacam situações em que eu estou brincando de bola com a amiga, o irmão brincando de carrinho, com o cachorro, amigo do irmão andando de skate e eu no balanço. "Os balanços como espaço de jogo, por sua autonomia e funcionamento, são por excelência, estimuladores da imaginação e criatividade". (NEGRINE, 2014, p.131). Por este motivo, uma das minhas brincadeiras prediletas era exatamente o balanço, pois me despertava uma sensação de liberdade, e imaginava que poderia voar, como nas histórias dos super heróis e contos de fada.

É importante ressaltar que as imagens contidas na sacola retratam apenas algumas das brincadeiras que eu participava, sendo que posteriormente, será relatado com detalhes os demais jogos e brincadeiras praticadas.

Alguns tecidos escolhidos para confeccionar a sacola foram comprados e o restante consegui com minha mãe e tia (ambas residem em Formigueiro) sendo que minha tia ajudou na parte da costura e acabamento, pois não tinha ideia de como costurá-la, além de não possuir máquina de costura e não saber costurar. Então, fui na casa da minha tia com os tecidos em mãos e ela, pacientemente, me passou algumas dicas de como iniciar a costurar (claro, ela fez a maior parte do trabalho, mas o importante é que, dentro do possível, consegui costurar algo). Alguns detalhes em bordado, minha mãe fez, uma vez que, fazia bordados em ponto cruz.

Acredito que a etapa mais difícil de construção da sacola foi a parte da costura e acabamento, pois como mencionei anteriormente, não tenho nenhuma habilidade na costura. Minha tia, teve um papel fundamental nesse processo, pois quando era mais jovem, costurava para amigas, vizinhas e família, e assim, contribuiu

\footnotetext{
${ }^{3}$ Está em primeira pessoa, porque se trata de uma escrita baseada em um relato autobiográfico.
} 
imensamente para que a confecção da minha bolsa, de fato, se concretizasse. Minha contribuição nessa parte foi mínima, mas percebi que costurar profissionalmente não é fácil. Gostei mesmo de desenhar os moldes das imagens que coletei na internet e na escolha dos tecidos da sacola. Enfim, toda a etapa de pesquisa foi extremamente prazerosa e fiz uma viagem nostálgica ao meu passado, ou melhor, na fase em que não tinha nenhuma preocupação com a vida, em que minha única função como criança, era estudar e me divertir muito, brincando!

Por fim, após a confecção da sacola, a próxima etapa seria mostrá-la para uma criança. Como não tenho filhos ainda, falei com minha vizinha, que reside no apartamento acima do meu, contei a respeito da minha sacola pedagógica, e, então, pedi a autorização a ela para mostrá-la a sua filha, Camila, de 5 anos. Como ela aceitou minha proposta, fui ao seu apartamento no outro dia fazer a atividade com a Camila. Assim, coloquei dentro da sacola pedagógica, livros infantis, caderno, lápis de cor, giz de cera, adesivos, canetinhas, ursos de pelúcia (pois não tenho mais bonecas no meu apartamento, algumas que ainda possuo, estão na casa dos meus pais, em Formigueiro). Logo que cheguei, a Camila já me conheceu, porque já havia conversado com ela pelos corredores do nosso prédio. Deste modo, apresentei-me novamente, e neste momento, nem precisei mostrar a sacola, pois ela percebeu de imediato, e já fez inúmeras indagações sobre ela, como: "Essa bolsa é sua"? "O que tem nela"? "Posso olhar"? "Ela é muito linda"!

A espontaneidade dela deixou-me muito à vontade, e logo em seguida, sentei no tapete da sala e disse: "Camila, a bolsa é minha sim! E sabe porque eu a trouxe aqui? Porque ela é muito especial, e quando eu era pequenina que nem você, eu brincava de todas essas brincadeiras que estão desenhadas aqui na frente da sacola, está vendo? "E é claro que você pode olhar, principalmente ver o que tem dentro dela. Mas primeiro, vou te contar sobre a história da minha sacola, pode ser?" Eu a estava observando, e enquanto eu falava, Camila se mostrou muito atenta e silenciosa.

$\mathrm{E}$, foi a partir disso, que comecei a contar, com uma certa nostalgia, sobre a história da minha infância, das brincadeiras de boneca, de bola, no balanço da pracinha, com os cachorrinhos, sempre falando e mostrando os desenhos estampados na frente da sacola. Depois, perguntei a ela se ela gostava de brincar dessas mesmas coisas, então, Camila disse que sim, mas que gostava mais de brincar de boneca e no balanço. E a nossa conversa foi fluindo, ela mostrou todas as suas bonecas e brinquedos, no geral. Ela ficou encantada com a sacola, perguntando 
quem fez, ou onde a comprei, e seu eu podia emprestar a bolsa a ela. Então comentei: "Claro que posso te emprestar, mas agora vamos fazer uma atividade bem legal?". Ela balançou a cabeça, dizendo que "sim". "Pois bem, olha só o que eu coloquei dentro da sacola: lápis de cor, canetinhas, giz de cera, livros....Camila, com esse material, tu aceitas desenhar no papel algumas das tuas brincadeiras favoritas? "Ah, e depois tu me mostra teu desenho e podes escolher um dos livros, que te conto a história, pode ser? Ela aceitou na hora, desenhando bonecas, brincando com as colegas na escola, assistindo desenhos infantis e brincando com massa de modelar, fazendo comidinhas. Posteriormente, contei a história do "Menino Maluquinho", e assim, nossa tarde terminou de forma muito descontraída e proveitosa.

\subsubsection{Registro autobiográfico das brincadeiras}

Concomitante à confecção da sacola, fui escrevendo e rememorando o brincar na minha infância, que foi vivenciada em Formigueiro, cidade pequena perto de Santa Maria - RS. Era uma menina que gostava de brincar de boneca (com bebês e Barbie), professora, de esconde-esconde, de amarelinha. Minhas amigas eram especificamente minhas colegas de escola e uma vizinha. Nos reuníamos na minha casa ou na casa delas. Eu lembro que passávamos um turno inteiro brincando, já que no inverso, estudávamos na mesma escola. Mas minha brincadeira predileta era de casinha da Barbie, pois minha tia confeccionava roupas das mais variadas para a Barbie, então, tinha um orgulho imenso de mostrar para minhas amigas todas as roupinhas e acessórios que eu colecionava para a Barbie.

Mas também brincava de dar aulas para minhas outras bonecas na área da casa da minha mãe, que tinha (e tem até hoje) um espaço muito grande, com um portão, que eu podia fazer de quadro para escrever. Ficava encantada observando minha mãe ministrar suas aulas (cheguei até ser sua aluna) e quando ela preparava as aulas, permanecia ao seu redor, vendo o capricho do caderno e dos materiais. Segundo Gutton (2013), muitas vezes a criança se espelha nas profissões dos pais, brincando de imitar o trabalho do pai ou da mãe, o que representará, futuramente, suas profissões.

Brincava também com uma prima. Colocávamos o bebê no carrinho de bonecas e saíamos com ele para passear no sol, dávamos mamá, chupeta, trocávamos a fralda e as roupas. [...] "Agir, em uma brincadeira de boneca, como a 
mãe, por exemplo, significa repetir, por analogia, o que a mãe tantas vezes fez com ela em seu primeiro ano de vida" [...]. (MACEDO, p.07, 1995).

Tinha (e ainda tenho) um carinho muito grande pelo brinquedo "Balanço da Moranguinho" que ganhei da minha mãe (que possuía uma música parecida com aquelas caixinhas de música, e era possível o balanço se movimentar, dando "corda"). Ficava horas brincando com ele, na penteadeira do meu quarto, pois ficava encantada com o cheirinho de morango. Sempre gostei de balanço, e fui privilegiada, neste sentido, porque na frente da casa dos meus pais, em Formigueiro tinha uma pracinha pequena, mas com balanços, escorregador, carrossel, etc. Eu e minhas amigas seguidamente frequentávamos a pracinha durante a semana, ou depois que saíamos da aula.

Fazer comida com areia, pedrinhas e capim, também fez parte da minha infância. No pátio da casa da minha tia havia um amontoado de tijolos, e eu e meus primos inventávamos comidas nas panelinhas de plástico da minha prima. Apesar de alguns desentendimentos, às vezes, a respeito de quem ficaria com mais ingredientes, a nossa "casinha" era perfeita e a nossa comida mais ainda! Os bebês também degustavam nossas comidinhas!

Quando chegava as férias escolares, viajávamos para Carazinho visitar meus padrinhos e outros parentes, e eu e meus primos brincávamos de imitar os filmes de ação da época, adaptando o roteiro com personagens semelhantes aos tais filmes. Era uma correria e gritaria muito grande, e principalmente: a diversão e as risadas eram garantidas. $\mathrm{E}$ também brincávamos de imitar algumas bandas de rock, como os Beatles, pois meu padrinho tinha vários discos de vinil, deles. Como descreve Gutton: "a única razão de ser do brincar para a consciência daquele que brinca é o próprio prazer que nele se encontra". (p. 24, 2013).

Outro jogo presente nas nossas horas de lazer era o Banco Imobiliário, jogo de tabuleiro clássico da época. O jogo consiste na compra e venda de propriedades como bairro, casas, hotéis, empresas, vencendo o jogador que não for à falência, ou o jogador que tiver mais propriedades compradas em mãos. Ficávamos horas jogando, e lembro que ninguém ficava chateado se perdia, era um divertimento total, mas ao mesmo tempo, éramos atentos e concentrados no que se referia ao andamento do jogo. Macedo (1995) descreve que no jogo de regra, os competidores devem estar atentos, concentrados, serem habilidosos e terem boa memória. Assim, o jogo de regra é composto de significados em que o desafio é um determinante fator de 
competição. Ou seja, este jogo é caracterizado por inúmeras regras contendo cartas, dados e etapas.

Um jogo bem marcante foi o de Caçador, também chamado de Queimada, em que é praticado por dois times, cujo objetivo é eliminar o adversário atingindo-os ("queimando-os") com a bola. Brincávamos deste jogo no recreio da escola ou nas aulas de Educação Física, nos anos iniciais do Ensino Fundamental. O campo é dividido com uma linha central. Atrás da área de cada time ficava o espaço reservado para os jogadores "queimados" ou "prisioneiros". Deste modo, o Caçador retrata muito bem o caráter coletivo, também sendo denominado como jogo de regra, visto que os jogadores dependem uns dos outros para vencer o jogo. (MACEDO, 1995).

Foi uma época que jamais irei esquecer, pois me remete a lembrança da minha avó e tia (in memoriam), porque toda a semana estava lá, na casa da minha avó (que morava com essa minha tia) comentando entusiasmada, sobre a casinha da Barbie que havia montado, e claro, buscando as roupinhas que a tia havia feito.

Posso dizer com toda a certeza, que a minha infância foi repleta de atividades prazerosas, de amizades, de brincadeiras, de nostalgia. Resumindo: ela foi mágica!

\section{METODOLOGIA}

Este trabalho baseia-se no método autobiográfico, no qual, apresenta a tarefa de ressignificar o sentido da formação, pelo viés do sujeito integral, propondo fundamentos e bases para a transmutação ética e política dos conceitos que envolvem o ensinar e o aprender. Assim, esse tipo de pesquisa é um trabalho de investigação e de reflexão sobre os sujeitos da aprendizagem. (NÓVOA; 1992, p.24).

Neste sentido, o método autobiográfico aborda o reconhecimento da multiplicidade de dimensões que constituem o ser humano. Compreender a existência humana em diferentes níveis é aceitar que somos sujeitos físicos, sensíveis, de emoções, de ações, de afetividades, de atenção consciente, de cognição e de imaginação (JOSSO, 2008; 2010; 2016).

\section{RESULTADOS E DISCUSSÕES}

Reviver a nostalgia da minha infância foi um exercício mágico e especial, já que, como adultos, perdemos a noção de como se sentir criança novamente, e a disciplina de Lúdico e Criatividade I trouxe à tona lembranças boas de como essa época deve ser prazerosa e cativante para toda as crianças. Todo o processo de 
confecção da sacola pedagógica, e principalmente da atividade prática, que foi mostra-la a uma criança, revelou o quanto é essencial a ludicidade no cotidiano das crianças, tanto dentro do convívio familiar quanto da escola.

O brincar é enriquecedor na vida das crianças, uma vez que, proporciona momentos de interação entre elas, socialização, possibilitando que as crianças expressem, com isso, suas emoções e criatividade. Cabe ressaltar que as escolas devem proporcionar às crianças um ambiente lúdico, que favoreça o crescimento infantil, promova a interação social e enriqueça a imaginação das crianças, pois as crianças aprendem por meio de jogos e brincadeiras, transformando, assim, momentos divertidos em aprendizagens significativas.

\section{CONSIDERAÇÕES FINAIS}

A proposta da realização dessa atividade por meio da disciplina Lúdico e Criatividade I foi uma tarefa inusitada, pois não havia elaborado nenhum tipo de trabalho que retomasse minhas memórias da infância, ou seja, as minhas brincadeiras prediletas. A construção de toda a etapa da escrita, do registro autobiográfico e da sacola pedagógica foi muito prazeroso, dinâmico e envolvente, visto que, na medida que a elaboração da escrita se desenvolvia, as minhas lembranças afetivas vinham à tona, juntamente com a espontaneidade e nostalgia em descrever a etapa mais importante da minha vida.

Partindo desse pressuposto, por meio de leituras e das minhas vivências enquanto acadêmica do Curso de Pedagogia, estagiária e criança, percebi o quanto a ludicidade é essencial para o desenvolvimento integral da criança, desde o cognitivo, social, cultural, e por consequência, na sua aprendizagem. As atividades lúdicas são atrativas, despertam o imaginário dos alunos, possibilitando também, que a criança crie vínculos afetivos e sociais com os colegas.

\section{REFERÊNCIAS:}

GUTTON, Philippe. O Brincar da Criança: estudo sobre o desenvolvimento infantil/ tradução de Sonia Fuhrmann - Petrópolis, RJ: Vozes, 2013. - (Coleção Clássicos do Jogo). 
JOSSO, Marie-Christine. As histórias de vida como territórios simbólicos nos quais se exploram e se descobrem formas e sentidos múltiplos de uma existencialidade evolutiva singular-plural. In: PASSEGGI, Maria da Conceição (org.). Tendências da pesquisa (auto)biográfica. Natal, RN: EUFRN; São Paulo: Paulus, 2008.

JOSSO, Marie-Christine. Experiências de vida e formação. Natal: EDUFRN; São Paulo: Paulus, 2010.

JOSSO, Marie-Christine. Processo autobiográfico do conhecimento da identidade singular-plural e o conhecimento da epistemologia existencial. In: ABRAHÃO, Maria Helena Menna Barreto; FRISON, Lourdes Maria Bragagnolo; BARREIRO, Cristhianny Bento (orgs.). A nova aventura (auto)biográfica: Tomo I. Porto Alegre: EDIPUCRS, 2016.

MACEDO, Lino de. Os jogos e sua importância na escola. Cad. Pesq. São Paulo, n.93, p.5-10, maio 1995.

NÓVOA, Antônio. Os professores e as histórias da sua vida. In: NÓVOA, Antônio (Org.) Vidas de professores. Porto: Porto Editora, 1992. 